\title{
The Effects of Structural Shocks on Macroeconomic Fundamentals under Aggressive Monetary Policy: The Case of Turkey
}

\author{
Mahmut Sami Güngör ${ }^{1}$, Bülent Güloğluำ \\ ${ }^{1}$ Istanbul Technical University, Department of Economics, Instanbul, Turkey
}

\begin{tabular}{l}
\hline ARTICLE INFO \\
\hline Article History \\
Received 27 September 2019; \\
Accepted 23 October 2019 \\
\hline
\end{tabular}
Accepted 23 October 2019

JEL Classifications

$\mathrm{C} 11, \mathrm{E} 12, \mathrm{E} 52$ \author{
ABSTRACT

Purpose: \\ This study aims to investigate the impact of aggressive monetary policy in terms of \\ inflation on the effects of structural shocks over macroeconomic fundamentals in Turkey. \\ For this purpose, we estimate the basic new Keynesian model by using the Bayesian \\ method for the period of $2000 Q 1$ to 2019 Q 1 .
}

Design/methodology/approach:

We use the most recent quarterly dataset of the real gross domestic product index, consumer price index and short term interest rate for Turkey. The prior distribution of structural parameters and shock processes are determined according to the literature. Then, we estimate two different version of the basic new Keynesian model with six distinct chains of Metropolis-Hasting algorithm with each of 100000 draws. Finally, we examine the long term impact of aggressive monetary policy on the effects of structural shocks with the help of the unconditional variance decomposition. Besides, the short term and over time analysis are conducted via the conditional forecast error variance decompositions.

\section{Findings:}

The results of Bayesian impulse responses are consistent with theoretical framework of the new Keynesian synthesis. Besides, the historical shock decompositions of endogenous variables give valuable insight for the last twenty years of Turkish economy. The

Keywords:

New Keynesian Model, Bayesian Estimation, Monetary Policy Inertia, Aggressive Monetary Policy, Turkey empirical results show that aggressive monetary policy increases the effects of monetary policy shock on inflation while its impact on output gap and interest rate decreases at every quarter. Moreover, the aggressive monetary policy boosts the effects of supply shock on the variability of output gap over time.

Research limitations/implications:

If the Central Bank of Turkey intends to implement aggressive monetary policy to sustain price stability, the monetary authority should bear in mind that their effects on both the real sector and the short term interest rate will diminish.

Originality/value:

This study deals with the popular discussion about the aggressiveness of monetary authority in emerging countries with its own distinctive design.

\section{Introduction}

Monetary authorities in advanced economies (e.g., the Fed and the ECB) implement monetary policies with some inertia which come into view as gradual adjustment of policy interest rate in response to varying economic conditions (Woodford, 1999). The gradual fashion in monetary policy is often referred as monetary policy inertia or interest rate smoothing (Castelnuovo, 2007). Woodford (1999) indicates that the inertial behavior of the central bank results in optimal consequences. Besides, Christiano et al. (2008) show that the stabilizing effect of the monetary policy of the ECB was greater than the Fed by virtue of having more inertia in the monetary policy rule of the ECB. However, monetary authorities in emerging countries follow a different path from their counterparts in developed countries.

Monetary policy makers in emerging countries are often criticized in terms of their timing and the degree of their aggressiveness although they contend that monetary policy is implemented in accordance with their primary objectives which are generally to achieve and to maintain price stability. In 2018, the Central Bank of Turkey (CBT)

${ }^{\dagger}$ Corresponding Author: Mahmut Sami Güngör

e-mail: gungorma@itu.edu.tr 
were seriously criticized by the public opinion for the delayed intervention in response to the sudden decrease in the value of Turkish Lira. Then, the monetary committee of CBT raised the policy interest rate which is one-week repo auction rate 125 basis points and 625 basis points in the meeting of June and September of 2018 , respectively. Recently, it is again expected to dramatically decrease the policy interest rate in order to relax the credit channels in Turkey.

The level of these reactions might be due to delayed responses or because the CBT anticipates positive externalities from aggressive policies. In this regard, Lei and Tseng (2019) note that the monetary authority is more reluctant to amend its policy interest rate in case of increased uncertainty. Therefore, the probability of postponing monetary policy implementation is much higher in an emerging country relative to a developed country due to differences in uncertainty regarding their economies. To be more specific, compare the most recent policy interest changes in the US and Turkey: The Federal Open Market Committee (FOMC) decided to raise the policy rate by only 25 basis points whereas the monetary committee of CBT increased the policy interest rate 625 basis points in September, 2018. These figures apparently indicate the tremendous differences in the aggressiveness of monetary authority between developed and emerging countries. Whatever the reasons, the crucial issue is the potential effects of an aggressive monetary policy on the macroeconomic dynamics of an economy. Thus, we study the impact of an aggressive monetary policy on the effects of structural shocks over macroeconomic fundamentals during the last twenty years in Turkish economy.

The next section presents the buildings blocks of the basic new Keynesian model which is a workhorse model of modern macroeconomics. Third section provides information about the data set and the empirical findings. Third section consists of six subsections which include the Bayesian estimation of the benchmark and the aggressive monetary policy model, the Bayesian impulse response functions, the historical shock decompositions, the unconditional variance decomposition and the conditional forecast error variance decompositions. Finally, the last section presents the concluding remarks.

\section{The Theoretical Model}

In this study, we closely follow the standard notation of the basic new Keynesian model of Gali (2008). This model is sometimes called as a three equation new Keynesian model or a canonical new Keynesian model in the literature. Most of the new Keynesian macroeconomic models make use of this model as their starting point. Thus, it constitutes the fundamental structure of modern macroeconomic models. The building blocks of the model is presented below. ${ }^{1}$ This model has a simple framework to consider the relationships among monetary policy, business cycle and inflation (Gali, 2008).

The model has three types of agents: households who live infinitely and maximize their welfare considering their intertemporal budget constraint, firms who produce differentiated goods and maximize their profit taking into account nominal rigidities, and monetary authority who manage the monetary policy of the country (Gali, 2008).

The first building block of the model is the new Keynesian Phillips' curve which has a forward looking behavior and is derived from the Calvo (1983) model. The new Keynesian Phillips' curve is defined as follows:

$$
\pi_{t}=\beta E_{t} \pi_{t+1}+\kappa \tilde{y}_{t}+\varepsilon_{t}^{s} \quad(1)^{2}
$$

$\pi_{t}, E_{t} \pi_{t+1}$ and $\tilde{y}_{t}$ are current period inflation, expected inflation and current period output gap ${ }^{3}$, respectively. Although the basic new Keynesian model of Gali (2008) does not have any exogenous process in the new Keynesian Phillips' curve, we add the exogenous cost push shock in equation 1 to take into account the effects of shocks on inflation in line with Poutineau et al. (2015). The exogenous supply shock process is assumed as: $\varepsilon_{t}^{S}=\rho_{s} \varepsilon_{t-1}^{S}+\xi_{t}^{S}$ with $\xi_{t}^{S} \sim$ iid $N\left(0, \sigma_{s}^{2}\right) . \rho_{s}$ is the parameter of persistency of supply shock. In fact, equation 1 represents the aggregate supply side of the model.

The second building block of the model is the dynamic IS curve which is basically a log linearization of the Euler equation. The following equation is the dynamic IS curve in the model:

$$
\tilde{y}_{t}=E_{t} \tilde{y}_{t+1}-\frac{1}{\sigma}\left(i_{t}-E_{t} \pi_{t+1}-r_{t}^{n}\right)+\varepsilon_{t}^{d}
$$

\footnotetext{
${ }^{1}$ Interested reader can look into the details of the micro foundations and the derivation of the basic new Keynesian model in Gali (2008) or Gali (2015). In spite of the notational differences, Walsh (2003) provides a helpful material for the basic new Keynesian model.

${ }^{2}$ Where $\kappa \equiv \lambda\left(\sigma+\frac{\varphi+\alpha}{1-\alpha}\right), \lambda \equiv \frac{(1-\theta)(1-\beta \theta)}{\theta} \Theta$ and $\quad \Theta \equiv \frac{1-\alpha}{1-\alpha+\alpha \epsilon} \cdot \alpha, \beta, \epsilon, \varphi, \sigma, \theta$ are capital share, discount factor, elasticity of substitution, Frisch elasticity, relative risk aversion and Calvo parameter. All parameters are positive in this study.

${ }^{3} \tilde{y}_{t} \equiv y_{t}-y_{t}^{n}$ where $y_{t}^{n}=\psi_{y a} a_{t}+\psi_{y}$,

$\psi_{y} \equiv-\frac{(1-\alpha)(\mu-\log (1-\alpha))}{\sigma(1-\alpha)+\varphi+\alpha}$ and $\mu=\log \left(\frac{\epsilon}{\epsilon-1}\right)$.
} 
$\tilde{y}_{t+1}, i_{t}, r_{t}^{n}$ are next period output gap, current period interest rate, and the natural rate of interest rate ${ }^{4}$, respectively. Actually, Gali (2008) does not include any exogenous process in the dynamic IS curve equation of the basic new Keynesian model. However, we include the exogenous demand shock process with $\mathrm{AR}(1)$ form in the model in order to capture the effects of demand shock following the study of Poutineau et al. (2015). This exogenous process is described as: $\varepsilon_{t}^{d}=\rho_{d} \varepsilon_{t-1}^{d}+\xi_{t}^{d}$ with $\xi_{t}^{d} \sim$ iid $N\left(0, \sigma_{d}^{2}\right) . \rho_{d}$ is the parameter of persistency of demand shock. Indeed, equation 2 stands for the aggregate demand side of the model.

Final building block of the model is the monetary policy schedule which is represented by the simple form of Taylor's rule. The model assumes that the monetary authority sustains the monetary policy compatible with the Taylor's rule which is characterized by the following equation:

$$
i_{t}=\phi_{\pi} \pi_{t}+\phi_{y} \tilde{y}_{t}+\varepsilon_{t}^{m}
$$

$\phi_{\pi}$ and $\phi_{y}$ are the feedback parameter of inflation and output gap in Taylor's rule, respectively. These parameters measure the influence of inflation and output gap in monetary policy rule. The exogenous variable $\varepsilon_{t}^{m}$ is described as the monetary policy shock defined as: $\varepsilon_{t}^{m}=\rho_{m} \varepsilon_{t-1}^{m}+\xi_{t}^{m}$ with $\xi_{t}^{m} \sim$ iid $N\left(0, \sigma_{m}^{2}\right) . \rho_{m}$ is the parameter of persistency of monetary policy shock. In this framework, equation 3 exemplifies the monetary policy rule controlled by monetary authority.

In addition to three structural equations described from equation 1 to equation 3, the standard basic new Keynesian model has another exogenous process related productivity or technology. This exogenous process represents the total factor productivity shock which is described as follows: $a_{t}=\rho_{a} a_{t-1}+\xi_{t}^{a}$ with $\xi_{t}^{a} \sim i i d N\left(0, \sigma_{a}^{2}\right)$. $\rho_{a}$ is the parameter of persistency of total factor productivity shock. The log linearization of the aggregate production function is as follows: $y_{t}=a_{t}+(1-\alpha) n_{t}$ where $n_{t}$ is equilibrium level of employment.

\section{Data and Findings}

\subsection{Data}

We use the most recent quarterly dataset of the real gross domestic product index (GDPI, 2010=100), consumer price index $(\mathrm{CPI}, 2010=100)$ and short term interest rate during the period of 2000Q1 to 2019Q1 for Turkey. While both the real GDP index and the CPI are taken from the IMF International Financial Statistics, the short term interest rate (SIR) is from Oxford Economics. ${ }^{5}$ Table 1 shows the descriptive statistics of observable variables.

Table 1: Descriptive Statistics of Observable Variables

\begin{tabular}{lccc}
\hline Variables & GDPI & SIR & CPI \\
\hline Mean & 105.69 & 26.0 & 99.25 \\
Standard Deviation & 31.76 & 31.45 & 50.86 \\
Minimum & 56.97 & 5.71 & 16.20 \\
Maximum & 171.52 & 153.0 & 224.10 \\
Skewness & 0.38 & 2.56 & 0.47 \\
Kurtosis & 2.06 & 8.97 & 2.60 \\
Observation & 77 & 77 & 78 \\
\hline
\end{tabular}

Before we estimate the model with the Bayesian methods, we do some transformation on the dataset. First of all, real GDP index and CPI are seasonally adjusted by using the Census X-13 procedure. Then, the cyclical component of seasonally adjusted real GDP index is extracted using two-sided Hodrick-Prescott ${ }^{6}$ (HP) filter ${ }^{7}$. In line with the suggestions of Pfeifer (2018), we do the following computations:

${ }^{4}$ If we assume $y_{t+1}=y_{t}^{n}$ and plug the above definition of natural output into the real interest rate equation $\left[r_{t}^{t}=\right.$ $\left.\rho+\sigma E_{t} \Delta y_{t+1}^{n}\right]$, we will get $r_{t}^{n}=\rho+\sigma E_{t}\left[\psi_{y a} a_{t}+\psi_{y}-\psi_{y a} a_{t-1}-\psi_{y}\right]=\rho+\sigma \psi_{y a} E_{t} \Delta a_{t+1} \quad$ where $\quad \psi_{y a} \equiv$ $\frac{1+\varphi}{\sigma(1-\alpha)+\varphi+\alpha}$.

5 Thomson Reuters Datastream codes are TKI99BV.F, TKQ64...F, and TKXRSHR.R for real GDP index, CPI, and short term interest rate, respectively.

${ }^{6}$ This procedure is resemble to de-trending of the data (e.g. $\left.y_{t}^{o b s}=\log \left(y_{t}^{\text {data }}\right)-\log \left(y_{t}^{\text {trend }}\right)\right)$. This filter gives the deviations of $\log$ output from the long-term trend and has zero mean. 
$\begin{array}{ll}\text { i. } & \pi_{t}^{o b s}=\log \left(\frac{c p i_{t}^{\text {data }}}{c p i_{t-1}^{\text {data }}}\right)-\text { mean }\left(\log \left(\frac{c p i_{t}^{\text {data }}}{c p i_{t-1}^{\text {data }}}\right)\right) \\ \text { ii. } & i_{t}^{o b s}=\log \left(1+\frac{i_{t}^{\text {data }}}{4 \times 100}\right)-\text { mean }\left(\log \left(1+\frac{i_{t}^{\text {data }}}{4 \times 100}\right)\right)\end{array}$

With the above calculation, we implicitly assume the steady state values of inflation ${ }^{8}$ and short term interest rate are their long run mean. These computations are actually demeaning of the related data.

\subsection{Bayesian Estimation of the Benchmark Model}

Bayesian estimation have become popular especially in applied macroeconomics over the last twenty years with the help of increasing the computational performance of computers. Macroeconomists have also made considerable efforts on Bayesian techniques because of its computational power to estimate medium or large scale dynamic stochastic general equilibrium models (DSGE) using Markov chain Monte Carlo simulators (Guerron-Quintana and Nason, 2013). Smets and Wouters (2003, 2007), An and Schorfheide (2007) and Benchimol and Fourçans (2012) are among the several prominent examples of studies applied Bayesian methods to estimate their models in macroeconomics. In this section of the study, we do not plunge into the tedious and laborious world of the Bayesian estimation. Dejong and Chetan (2007), Guerron-Quintana and Nason (2013) and (Fernández-Villaverde, 2010) give the detailed discussion about Bayesian estimation of DSGE models.

Following the literature, the parameters of capital share $(\alpha)$, discount factor $(\beta)$, elasticity of substitution $(\epsilon)$, Frisch elasticity $(\varphi)$ and relative risk aversion $(\sigma)$ are calibrated to $0.33,0.99,6,1,1$, respectively. The prior distribution of remaining structural parameters and shock processes in the model are given in Table 2. The calibration of both the structural parameters and the shock processes comes from Gali (2008), Benchimol and Fourçans (2012), and Poutineau et al. (2015). We assume the standard errors of shocks are to follow inverse gamma distributions in order to force the parameters to be greater than zero. Besides, we prefer a beta distribution for the persistency parameters of shocks, the feedback parameter of output gap and the Calvo parameter owing to the fact that these parameters should fall between zero and one. On the other hand, the feedback parameter of inflation that should be greater than one is assumed to be follow a normal distribution.

The model presented in the second section is estimated ${ }^{9}$ by using Bayesian techniques with the data of Turkey for the period of 2000Q1 to 2019Q1. For the posterior distribution, we prefer to use six distinct chains of Metropolis-Hasting $(\mathrm{MH})$ algorithm with each of 100000 draws ${ }^{10}$. Furthermore, we opt to employ the optimizer of Chris Sim's csminwel for the mode computation. Any value between 0.2 and 0.4 is referred to the suitable acceptance rate in the literature. Roberts et al. (1997) indicate the optimal acceptance rate is around 0.234 under general conditions. The average acceptance rate ${ }^{11}$ per chain is in the interval between 0.233 and 0.238 for the benchmark model. Table 2 shows the posterior distribution of structural parameters and shock processes and a 90 percent Highest Posterior Density (HPD) interval.

\footnotetext{
${ }^{7}$ We use the standard value of $\lambda$ which is 1600 for quarterly data.

${ }^{8}$ Inflation is calculated as follows: $\pi_{t}^{\text {data }}=\log \left(c p i_{t}^{\text {data }}\right)-\log \left(c p i_{t-1}^{\text {data }}\right)$. Due to the one period lag in the definition of inflation, we launch the period of consumer price index data from the fourth quarter of the year of 1999.

${ }^{9}$ We use the version 4.5.6 of Dynare software (Adjemian et al., 2018) with Matlab (R2018b) during the estimation procedure.

${ }^{10}$ We discard the first decile of the draws from $\mathrm{MH}$ algorithm at each chain. Besides, we opt to choose the value of scale parameter for the jumping distribution in $\mathrm{MH}$ algorithm as 0.75 .

${ }^{11}$ The exact acceptance ratio (in percent) for each chain is 23.344, 23.678, 23.478, 23.786, 23.371, 23.776, respectively.
} 
Table 2: Prior and Posterior distribution of structural parameters and shock processes

\begin{tabular}{cccccccc}
\hline & Prior Distribution & & \multicolumn{3}{c}{ Posterior Distribution } \\
\cline { 2 - 8 } Parameter & Law & Mean & Std. & Mode & Mean & $10 \%$ & $90 \%$ \\
\hline$\theta$ & Beta & 0.67 & 0.05 & 0.6740 & 0.6699 & 0.5880 & 0.7542 \\
$\phi_{\pi}$ & Normal & 1.50 & 0.50 & 2.0169 & 1.9959 & 1.7051 & 2.2765 \\
$\phi_{y}$ & Beta & 0.125 & 0.10 & 0.4392 & 0.5122 & 0.3105 & 0.7227 \\
$\rho_{s}$ & Beta & 0.75 & 0.10 & 0.7293 & 0.6936 & 0.5700 & 0.8238 \\
$\rho_{m}$ & Beta & 0.50 & 0.10 & 0.2267 & 0.2597 & 0.1583 & 0.3573 \\
$\rho_{d}$ & Beta & 0.75 & 0.10 & 0.8564 & 0.8445 & 0.7634 & 0.9339 \\
$\rho_{a}$ & Beta & 0.75 & 0.10 & 0.7787 & 0.7268 & 0.5460 & 0.9165 \\
$\xi_{t}^{s}$ & Invgamma & 0.02 & 2.00 & 0.0087 & 0.0093 & 0.0069 & 0.0115 \\
$\xi_{t}^{d}$ & Invgamma & 0.02 & 2.00 & 0.0150 & 0.0151 & 0.0096 & 0.0203 \\
$\xi_{t}^{m}$ & Invgamma & 0.02 & 2.00 & 0.0419 & 0.0435 & 0.0368 & 0.0501 \\
$\xi_{t}^{a}$ & Invgamma & 0.02 & 2.00 & 0.0093 & 0.0238 & 0.0048 & 0.0468 \\
\hline
\end{tabular}

According to the posterior mean of the Calvo price $\operatorname{parameter}^{12}(\theta)$, the average duration ${ }^{13}$ of pricing is approximately three period in Turkey. Besides, the highest value of posterior mean of persistency parameter is attributed to the demand shock with the value of 0.8445 . On the other hand, the monetary policy shock has the lowest value of posterior mean of persistency parameter with the value of 0.2597 . The reaction of the monetary authority to the deviation of inflation from its steady state is about 3.90 times greater than the reaction of those to the deviation of output gap from its steady state in Turkey with respect to the benchmark model. The posterior mean of the feedback parameter of inflation $\left(\phi_{\pi}\right)$ in the Taylor's rule is around 1.99 which is higher than the standard value ${ }^{14}$ in the literature. Thus, this empirical result shows that the monetary authority in Turkey follows the inflation stability policy ${ }^{15}$ which is consistent with the primary objective of the Central Bank of Turkey (CBT).

\subsection{Impulse Response Analysis}

The estimated Bayesian impulse response functions (IRFs) to the several structural shocks are given in Figure 1 to Figure 4. They are the mean impulse responses and the shaded areas shows the 90 percent HPD intervals (Pfeifer, 2017) which are actually the equivalent of a confidence interval in the Bayesian framework. We obtain these impulse responses from the estimation of the benchmark model. When the Bayesian IRFs are plotted, we only consider the observable variables which are output gap, short term interest rate and inflation for the benchmark model. The Bayesian IRFs of the aggressive monetary model are very similar to the ones from the benchmark model. That's why we only present the Bayesian IRFs of the benchmark version of the basic new Keynesian model for Turkey during the period of $2000 Q 1$ to 2019 Q 1 .

Figure 1 shows the effects of a one percent negative supply shock on the observable macroeconomic variables in the model. Firstly, this shock directly leads to an increase in inflation. Then, the monetary authority reacts this inflationary situation with the Taylor's rule by rising the short term interest rate. Since the rise in interest rate dominates the inflation rate the real interest rate increases. As a result, output falls below its natural level because of costly investment. On the other hand, the rise in interest rate reduces inflation over time. After fifteen quarters, the output gap returns its steady state level while the inflation reaches its long run level.

\footnotetext{
$12 \theta$ can be interpreted as the natural price stickiness index (Gali, 2008).

${ }_{13}$ This duration is calculated by the following formula: $(1-\theta)^{-1}$.

${ }_{14}$ The standard value of the feedback parameter of the Tayor's rule is 1.5 (Taylor, 1993, 1999).

${ }_{15}$ This result is also consistent with the findings for emerging countries, see (Popescu, 2014).
} 
Figure 1: The Impulse Responses to a Supply Shock
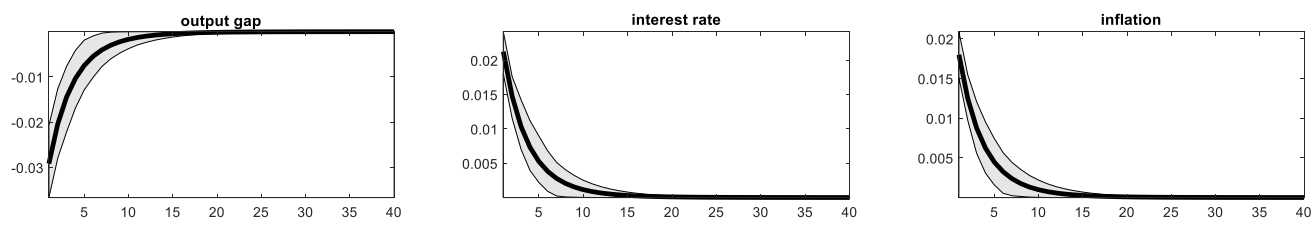

Figure 2 documents the impulse responses of a one percent positive demand shock on the observable macroeconomic variables in the model. The increase in economic activity owing to higher demand for goods and services results in both higher inflation and the positive output gap (i.e., where output is above its natural level). Due to the high inflation and the positive output gap, the Taylor's rule dictates the monetary authority to increase the interest rate. The effects of positive demand shock on the output gap, inflation and interest rate will vanish after twenty-five quarters and all of them return their natural levels.

Figure 2: The Impulse Responses to a Demand Shock
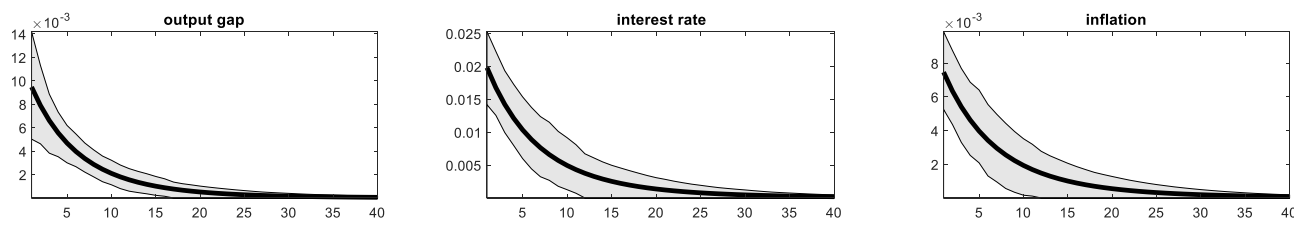

The consequences of a one percent contractionary monetary policy are given in Figure 3. This shock corresponds to a twenty-five basis points rise in short term interest rate in a quarter. Because of the price stickiness the real interest rate rises in the short run. This, in turn, leads to a holdup in consumption decisions of households and decreases the demand for goods and services in the economy. The deficiency of the overall demand create deflation in the economy. After short period of time, the monetary authority reacts the negative output gap and deflation in the economy by reducing the interest rate because of the Taylor's rule. Finally, the effects of a monetary policy shock on the observable macroeconomic variables in the model diminish after only five quarters and all of them return to their long run levels. Its effects vanish very quickly in the short run relative to the other shocks in the model.

Figure 3: The Impulse Responses to a Monetary Policy Shock
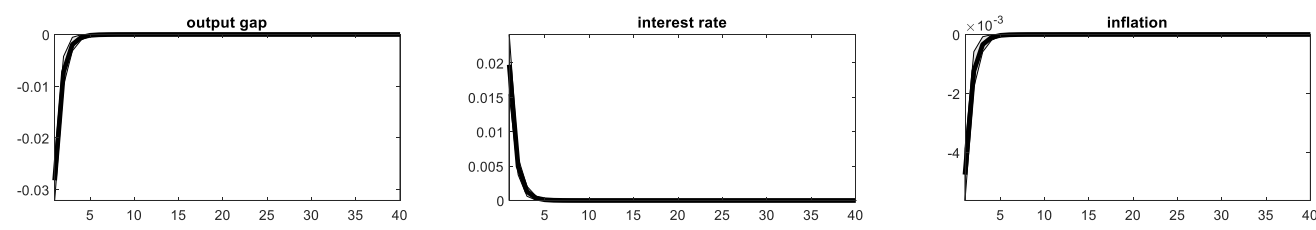

The impulse response functions of a positive total factor productivity shock (or, technology shock) are presented in Figure 4. This shock increases the natural level of output. Thus, it causes to decrease output gap. The monetary authority decreases interest rate on account of the negative output gap and the lower inflation. The effects of technology shock on macroeconomic variables diminish in the medium term and all observable endogenous variables return to the levels of their steady 
Figure 4: The Impulse Responses to a Total Factor Productivity Shock
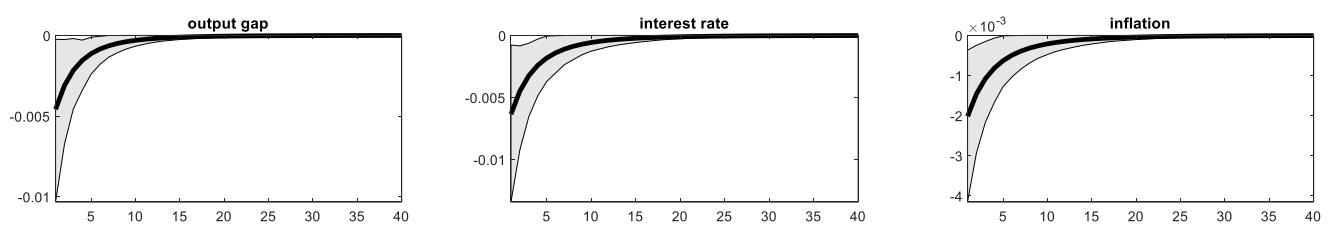

\subsection{Historical Shock Decomposition}

In the preceding section, the Bayesian IRFs presented the isolated effects of shocks on the observable endogenous variables. However, the shocks jointly occur and affect the macroeconomic variables in real life (Poutineau et al., 2015). In order to investigate the combined effects of the structural shocks in the model we analyze the historical shock decomposition of observable endogenous variables.

The historical shock decomposition of endogenous variable gives the contribution of the related smoothed shocks to the deviation of smoothed endogenous variable from its steady state which is depicted by the colored bars (Pfeifer, 2017). The historical shock decompositions of the observable endogenous variables in the benchmark model are given from Figure 5 to Figure 7 . Since these results resemble to those from the aggressive monetary policy model we do not present them separately. The contributions of the smoothed shocks of supply, demand, monetary policy and total factor productivity are displayed by blue, red, green and navy blue shaded area, respectively. The initial values box shaded by grey refers to the part of the deviations from steady state explained by the unknown initial value of the related variables rather than the smoothed shocks in the model (Pfeifer, 2017).

Figure 5 shows the historical shock decomposition of output gap between 2000Q1 and 2019Q1 in Turkey. The black line represents the deviation of the smoothed values of the output gap from its steady state. Before the 2001 crisis in Turkey, the most dominant shock on the output gap was the monetary policy shock. However, the crisis was transformed into a demand and supply shock during the crisis. The main reason of the catastrophic decline of output gap during the 2001 crisis was the supply shock. The 2001 crisis was actually emerged from the banking system crisis resulted in bankruptcy of some banks in Turkey. This crisis crunched the credit channels of Turkish real sector, and in turn, the supply side turned out to be the dominant factor in amplifying the crisis. On the other hand, before the 2008 financial crisis, the supply shock played an important role in ascending output gap. During the 2008 financial crisis, the composition of shocks in Turkey was somewhat different from the 2001 crisis. The monetary policy and demand shocks were the main sources of the decline during the 2008 financial crisis while the negative effects of supply shock were relatively small. Conversely, the demand shock was the major factor against the decline in output gap in Turkey during the 2001 crisis. The negative effects of demand shock on output gap during the 2008 financial crisis might be due to the decline in the volume of Turkish total international trade with either EU or advanced countries which were seriously affected by the crisis. Thus, the sources of this demand shock were mainly from the outside of Turkey in the course of the 2008 global financial crisis.

Figure 5: Historical Shock Decomposition of Output Gap

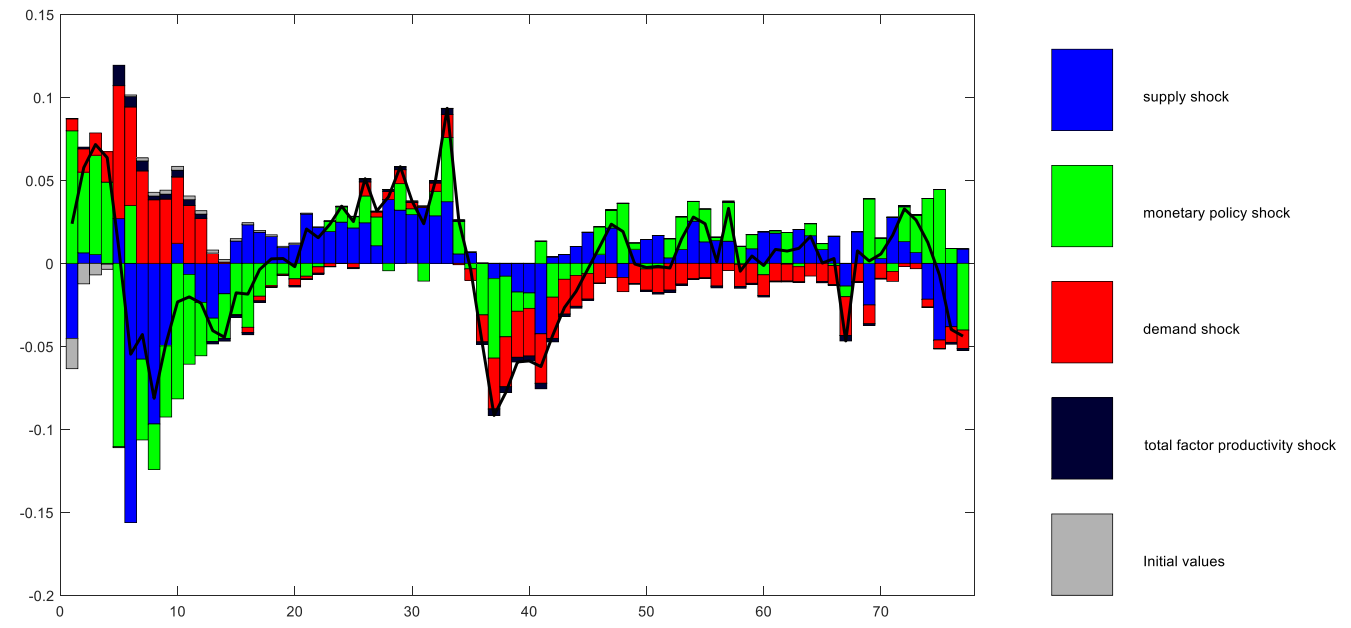

The historical shock decomposition of interest rate during the period of 2000Q1 to 2019Q1 in Turkey is given in Figure 6. Similar to Figure 5, the black line shows the deviation of the smoothed values of the short term interest rate 
from its steady state. The major driver of peaking the short term interest rate during the 2001 crisis in Turkey was the demand shock which preceded the supply shock. In addition to the demand shock, all other shocks contributed interest rate positively both during the 2001 crisis and the post crisis period. On the other hand, there were some unknown factors that caused interest rates to rise during the same period since this initial uncertainty in the model is expected to die out quickly. One of these unknown factors might be the fixed exchange rate regime in Turkey at that time. The monetary authority in Turkey tried to prevent both the rise in exchange rate parity and outflow of the foreign capital with the help of boosting the interest rate. Although the overnight rate reached its peak level, demand for foreign currencies continued. As a result, Turkish monetary authority quit the fixed exchange rate regime and let the exchange rate fluctuate in February, 2001. The effects of monetary policy shock on the deviation of the short term interest rate from its steady state were relatively small with respect to either the demand shock or the supply shock over time. It can be inferred that the demand shock was the most dominant determinant of the deviation of the short term interest rate over the whole period. Apart from this, the dynamic of the interest rate in Turkey during the 2001 crisis was somewhat different from the 2008 global financial crisis. Following the dot-com crisis in 2000 , the Fed started decreasing its policy interest rates in order to prevent the likelihood of a recession in the United States. While the low interest rate policy was rather moderate, it paved the way to housing bubble and the global financial crisis in 2008. Nevertheless, when the global financial crisis broke out, the Fed policy interest rates were already at low levels; and in order to prevent even a deeper crisis, the Fed as well as the ECB, and the Bank of England started following asset purchases or quantitative easing $(\mathrm{QE})$ programs. Hence, low interest rates at a global extent mark the monetary policy situation in 2008. ${ }^{16}$ Furthermore, interest rates are not expected to be increased when the dominant source of the crisis is demand shock. That's why the interest rate did not increase in Turkey during the 2008 global financial crisis as opposed to the 2001 crisis. On the other hand, the Turkish financial sector did not keep the risky financial derivatives in their balance sheet. Moreover, the soundness of Turkish banking sector was plausible level due to the lessons learned from the 2001 crisis. Thus, the contagion of the subprime crisis to Turkish economy was not realized. As a result, the credit channel of banking sector in Turkey did not crash during the 2008 financial crisis on the contrary the 2001 crisis.

\footnotetext{
${ }^{16}$ See Yağmur (2015) for a detailed discussion about the loose monetary policy of the Fed starting from the 2000 s, and
} how it triggered the 2008 global financial crisis. 
Figure 6: Historical Shock Decomposition of Interest Rate

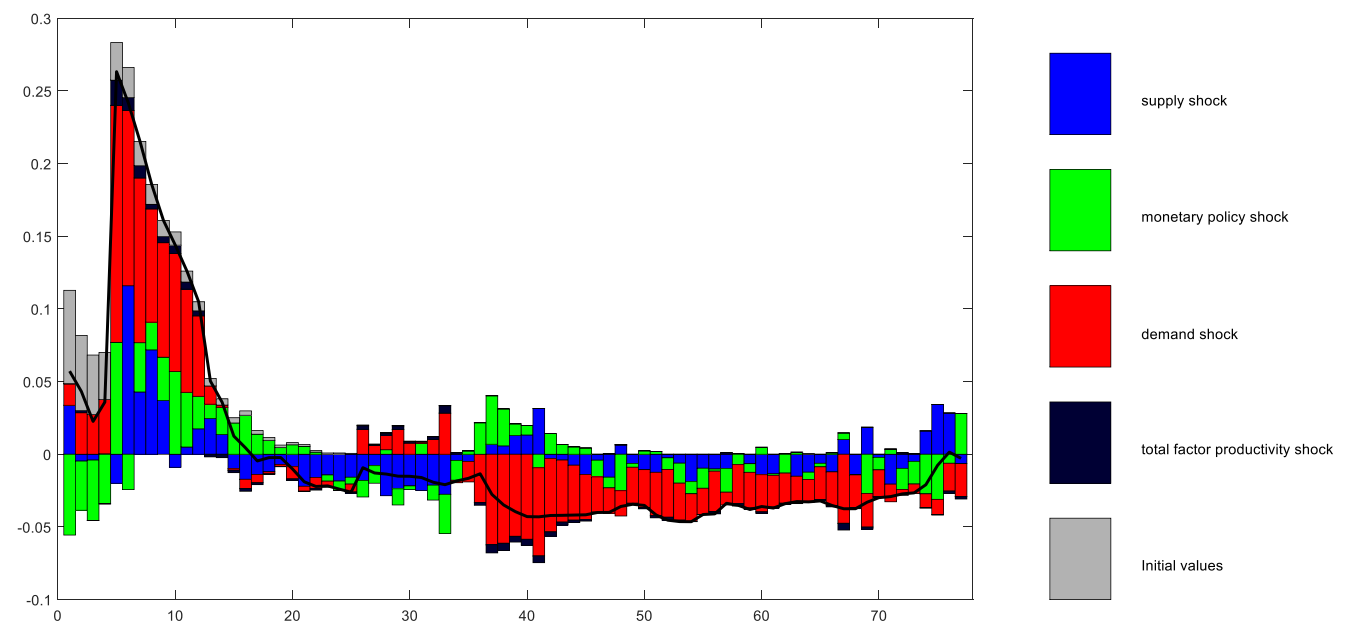

Figure 7 demonstrates the historical shock decomposition of inflation for the period of 2000Q1 to 2019Q1 in Turkey. The black line also depicts the deviation of the smoothed values of the inflation from its steady state. The monetary policy shock did not have any considerable impact on the deviation of the inflation form its long run level with respect to other shocks. Both the demand and supply shock are the dominant sources of rising inflation during the $2001 \mathrm{crisis}$. Before the 2008 global financial crisis, the major driver of the deviation of inflation from its steady state is the supply shock. On the other hand, the demand shock contributed the deviation of the inflation from its steady state more than any other shocks during the 2008 financial crisis. Furthermore, the demand shock was the dominant source of low inflation during and after the 2008 financial crisis. Moreover, the sudden increase in inflation at the year of 2018 in Turkey was mostly related to the supply shock. This was due to the foreign exchange rate crisis at the last year. At the beginning of the year of 2018, one United States dollar was 3.77 Turkish lira (TL), however, its value reached to 6.88 TL over time and was 5.26 TL at the end of that year. The depreciation of TL caused to increase the cost of intermediate goods and production in Turkey shrank due to its high imported intermediate good dependency. The deviation of inflation from its steady state began to decline from the first quarter of 2019 with the almost equal contributions of supply, demand and monetary policy shock.

Figure 7: Historical Shock Decomposition of Inflation

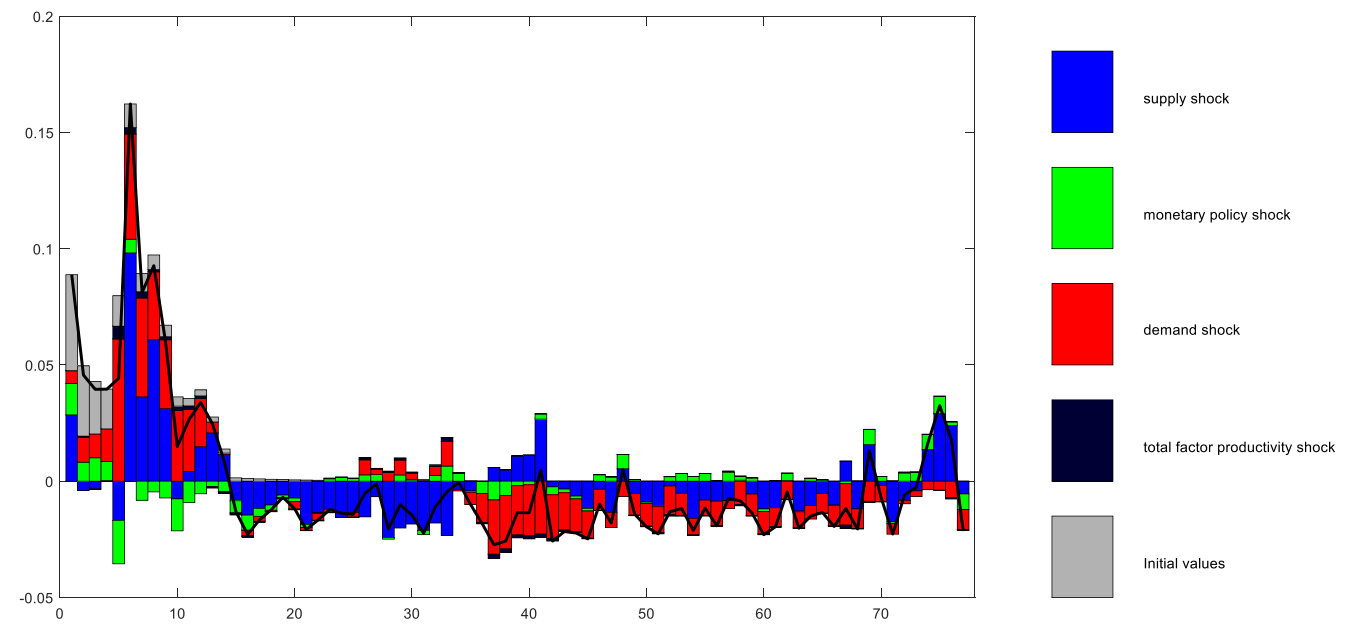

\subsection{Bayesian Estimation of the Aggressive Monetary Policy Model}


In this part of the study, we again estimate the basic new Keynesian model with the help of Bayesian methods for Turkey for the period 2000Q1 to 2019Q1. The main difference of this model from the benchmark model is the prior distribution of the feedback parameter of inflation in Taylor's rule. In this manner, we increase the feedback parameter of inflation $\left(\phi_{\pi}\right)$ three folds from 1.5 to 4.5 in order to investigate the effects of the aggressive monetary policy on exogenous structural shocks defined in the model. All previous assumptions regarding the prior distribution are valid except the prior mean of the feedback parameter of inflation in the aggressive monetary policy model. The prior distribution of structural parameters and shock processes are given in Table 3.

We maintain the previous estimation settings which are the use of six distinct chains of MH algorithm with each of 100000 draws and the Chris Sim's csminwel optimizer for the mode computation in the aggressive monetary policy version of the benchmark model. The average acceptance rate ${ }^{17}$ per chain is in the interval 0.233 and 0.236 for the aggressive monetary policy model. Table 2 presents the posterior distribution of structural parameters and shock processes and a 90 percent HPD interval.

The average duration of pricing increases only in negligible amounts ${ }^{18}$ when the level of aggressiveness of monetary authority raises. Similarly, with the benchmark model, the demand shock has the highest value of posterior mean of persistency parameter while the monetary policy shock has the lowest one. Furthermore, all the values of posterior mean of persistent parameters rise when the monetary authority implements the aggressive monetary policy in Turkey. The reaction of the monetary authority to the deviation of inflation from its steady state is approximately 4.25 times larger than the reaction of those to the output gap deviation from its steady state in the aggressive monetary policy model. The magnitude of the difference in the reactions of the monetary authority to the steady state deviations of both inflation and output gap rises about nine percent when the aggressive monetary policy is implemented in Turkey. The posterior mean of the feedback parameter of inflation in Taylor's rule increases from 1.99 in the benchmark model to 2.44 in the aggressive monetary policy model. This result indicates that the extent of the sensitivity of inflation in monetary policy (or the level of inflation stability policy) enhances by virtue of boosting the aggressiveness of monetary policy in Turkey.

Table 3: Prior and Posterior distribution of structural parameters and shock processes

\begin{tabular}{cccccccc}
\hline & Prior Distribution & \multicolumn{7}{c}{ Posterior Distribution } \\
\cline { 2 - 7 } Parameter & & & & & & \multicolumn{2}{c}{ HPD Interval } \\
\cline { 6 - 8 } & Law & Mean & Std. & Mode & Mean & $10 \%$ & $90 \%$ \\
\hline$\phi_{\pi}$ & Beta & 0.67 & 0.05 & 0.6740 & 0.6707 & 0.5869 & 0.7525 \\
$\phi_{y}$ & Normal & 4.50 & 0.50 & 2.4017 & 2.4429 & 2.0771 & 2.8116 \\
$\rho_{s}$ & Beta & 0.125 & 0.10 & 0.5432 & 0.5753 & 0.3952 & 0.7672 \\
$\rho_{m}$ & Beta & 0.75 & 0.10 & 0.7326 & 0.7113 & 0.5975 & 0.8287 \\
$\rho_{d}$ & Beta & 0.50 & 0.10 & 0.2464 & 0.2678 & 0.1721 & 0.3627 \\
$\rho_{a}$ & Beta & 0.75 & 0.10 & 0.8713 & 0.8573 & 0.7864 & 0.9408 \\
$\xi_{t}^{s}$ & Beta & 0.75 & 0.10 & 0.7795 & 0.7473 & 0.5787 & 0.9215 \\
$\xi_{t}^{d}$ & Invgamma & 0.02 & 2.00 & 0.0087 & 0.0092 & 0.0071 & 0.0113 \\
$\xi_{t}^{m}$ & Invgamma & 0.02 & 2.00 & 0.0163 & 0.0161 & 0.0115 & 0.0210 \\
$\xi_{t}^{a}$ & Invgamma & 0.02 & 2.00 & 0.0472 & 0.0491 & 0.0403 & 0.0575 \\
\hline & Invgamma & 0.02 & 2.00 & 0.0093 & 0.0258 & 0.0045 & 0.0550 \\
\hline
\end{tabular}

\footnotetext{
${ }_{17}$ The exact acceptance ratio (in percent) for each chain is $23.676,22.132,22.81,22.887,23.4,22.84$, respectively.

${ }_{18}$ The precise value of the average duration of pricing is 3.029 periods for the benchmark model while its value is around 3.036 periods for the aggressive monetary model.
} 


\subsection{Forecast Error Variance Decomposition}

In this section we investigate the impact of aggressive monetary policy in terms of inflation on the effects of shocks over macroeconomics fundamentals in Turkey with the help of the forecast error variance decompositions (FEVDs) of each observable endogenous variables at the mean of the posterior distribution with respect to the exogenous structural shocks. Firstly, the long term analysis is conducted via the unconditional variance decomposition. Then, the short term analysis is made via the first period conditional variance decomposition. Finally, we plot the graphs of the conditional forecast error variance decompositions of observable endogenous variables for the benchmark and the aggressive monetary model so as to compare them over time.

\subsubsection{Long Term Analysis}

The unconditional variance decomposition at the posterior mean for the benchmark and the aggressive monetary model is given in Table 4. For the benchmark model, more than fifty percent of output gap variability is explained by the supply shock. The monetary policy shock account for one third of this variability. On the other hand, the demand and supply shocks contribute the variation of interest rate approximately three out of four. The dominant source of the variability in inflation is from the supply shock which is accounted for more than seventy-five percent of change in inflation. The effect of supply shock on output gap rises while its effects on both interest rate and inflation decrease under the aggressive monetary policy. Besides, the aggressive monetary policy reinforces the impact of demand shock on both interest rate and inflation while it does not considerably change the effect of this shock on output gap. Moreover, the aggressiveness of monetary authority reduces the effects of monetary policy shock on output gap and interest rate. However, the impact of monetary policy shock on inflation increases when the monetary authority implements more aggressive policy.

\subsubsection{Short and Over Time Analysis}

Table 5 shows the conditional variance decomposition at the mean of the posterior distribution for the first period. In the short run, the effects of monetary policy shock on all observable endogenous variables increase for the benchmark and aggressive monetary policy model relative to the long run. On the other hand, the effects of both supply and demand shocks on all observable endogenous variables reduce except the effect of supply shock on inflation in the first quarter relative to the infinite time horizon for the both model. Besides, the impact of aggressive monetary policy on the effects of shocks in the short run are very similar to the consequences of the long run for the supply and monetary policy shock. The magnitudes of the difference in FEVDs between the benchmark model and the aggressive model are smaller in the short run than the long run. However, by contrast with the long run results the effects of demand shock on both output gap and inflation decreases in the short run in the case of having aggressive monetary policy.

Table 4: Posterior Mean Unconditional Variance Decomposition (in percent)

\begin{tabular}{|c|c|c|c|c|}
\hline & $\begin{array}{c}\text { Supply Shock } \\
\left(\xi_{t}^{S}\right) \\
\end{array}$ & $\begin{array}{c}\text { Demand Shock } \\
\left(\xi_{t}^{d}\right) \\
\end{array}$ & $\begin{array}{l}\text { MP Shock } \\
\quad\left(\xi_{t}^{m}\right) \\
\end{array}$ & $\begin{array}{c}\text { TFP Shock } \\
\left(\xi_{t}^{a}\right)\end{array}$ \\
\hline \multicolumn{5}{|c|}{ Benchmark $\left[\phi_{\pi}=1.5\right]$} \\
\hline Output Gap $\left(\tilde{y}_{t}\right)$ & 57.65 & 6.03 & 34.68 & 1.64 \\
\hline Interest Rate $\left(i_{t}\right)$ & 40.14 & 35.64 & 20.50 & 3.72 \\
\hline Inflation $\left(\pi_{t}\right)$ & 77.57 & 17.58 & 3.68 & 1.17 \\
\hline \multicolumn{5}{|c|}{ Aggressive Monetary Policy $\left[\phi_{\pi}=4.5\right]$} \\
\hline Output Gap $\left(\tilde{y}_{t}\right)$ & 61.73 & 6.81 & 30.90 & 0.56 \\
\hline Interest Rate $\left(i_{t}\right)$ & 28.80 & 54.29 & 15.34 & 1.58 \\
\hline Inflation $\left(\pi_{t}\right)$ & 67.99 & 27.30 & 4.18 & 0.53 \\
\hline
\end{tabular}

Table 5: First Period Posterior Mean Conditional Variance Decomposition (in percent)

\begin{tabular}{lcccc}
\hline & $\begin{array}{c}\text { Supply Shock } \\
\left(\xi_{t}^{S}\right)\end{array}$ & $\begin{array}{c}\text { Demand Shock } \\
\left(\xi_{t}^{d}\right)\end{array}$ & $\begin{array}{c}\text { MP Shock } \\
\left(\xi_{t}^{m}\right)\end{array}$ & $\begin{array}{c}\text { TFP Shock } \\
\left(\xi_{t}^{a}\right)\end{array}$ \\
\cline { 2 - 5 } Benchmark $\left[\boldsymbol{\phi}_{\boldsymbol{\pi}}=\mathbf{1 . 5}\right]$ & & & & \\
Output Gap $\left(\tilde{y}_{t}\right)$ & 47.31 & 5.64 & 44.93 & 2.12 \\
Interest Rate $\left(i_{t}\right)$ & 34.42 & 30.88 & 29.70 & 5.01 \\
Inflation $\left(\pi_{t}\right)$ & 78.16 & 14.46 & 5.81 & 1.57
\end{tabular}




\section{Aggressive Monetary Policy $\left[\phi_{\pi}=4.5\right]$}

\begin{tabular}{lcccc} 
Output Gap $\left(\tilde{y}_{t}\right)$ & 54.43 & 3.11 & 41.54 & 0.91 \\
Interest Rate $\left(i_{t}\right)$ & 33.96 & 32.01 & 29.52 & 4.51 \\
Inflation $\left(\pi_{t}\right)$ & 77.77 & 13.34 & 7.42 & 1.48 \\
\hline
\end{tabular}

With the aim of comparing the benchmark model to the aggressive monetary policy model with respect to the impact of structural shocks on observable endogenous variables we plot the conditional forecast error variance decompositions of output gap, short term interest rate and inflation over the next forty quarters. The red line depicts the benchmark model and the blue line represents the aggressive monetary policy model from Figure 8 to Figure 10 . Figure 8 represents the conditional forecast error variance decomposition of output gap. The aggressive monetary policy boosts the effects of supply shock on output gap over time. However, it dampens the impact of shocks of demand, monetary policy and total factor productivity on output gap at every quarter.

The conditional forecast error variance decomposition of interest rate is given in Figure 9. The effects of supply and monetary policy shocks on interest rate decrease, however, the size of the reduction of the monetary policy is relatively small in the case of aggressive monetary policy. On the other hand, the aggressiveness of monetary authority reinforces the effects of demand and total factor productivity shocks on interest rate over time. The impact of both demand and monetary policy shocks do not change over about four quarters with respect to the benchmark model in the case of aggressive monetary policy.

Figure 10 depicts the conditional forecast error variance decomposition of inflation over time. Initially, the effect of supply shock on inflation does not change under the aggressive monetary policy for seven quarters, then its effect diminishes. Besides, the impact of demand shock on inflation decreases with the aggressive monetary policy. On the other hand, the impact of monetary policy and total factor productivity shocks on inflation reduce in the case of implementing aggressive monetary policy.

As a result, the aggressive monetary policy increases the effects of monetary policy shock on inflation while its impact on output gap and interest rate decreases in each period. Because the primary objective of the CBT is to achieve and maintain price stability, rise in the aggressiveness of monetary authority results in consistent outcome with the objective of the CBT in terms of inflation. However, the aggressive monetary policy decreases the effects of monetary policy shock on both interest rate and output gap which correspond to the real sector. In other words, if the CBT intends to implement aggressive monetary policy to sustain price stability, the monetary authority should bear in mind that their effects on both the real sector and the short run interest rate will diminish. This result is consistent with the real life situation. The monetary policy committee of the CBT reduced the policy interest rate by 425 basis points (from 24 percent to 19.75 percent) in the meeting of $25^{\text {th }}$ July of 2019. The immediate effect of this policy on consumer loan rate did not meet the expectation of monetary authority. The average consumer loan rate only decreased from 26.46 percent to 26.34 percent the following week of the decision. Nevertheless, the state-owned banks simultaneously initiated a policy of lowering real estate loan rates in order to stimulate private banks to reduce their loan rates. Then, all types of average loan rates started to decrease over time. 
Figure 8: Conditional Forecast Error Variance Decomposition of Output Gap
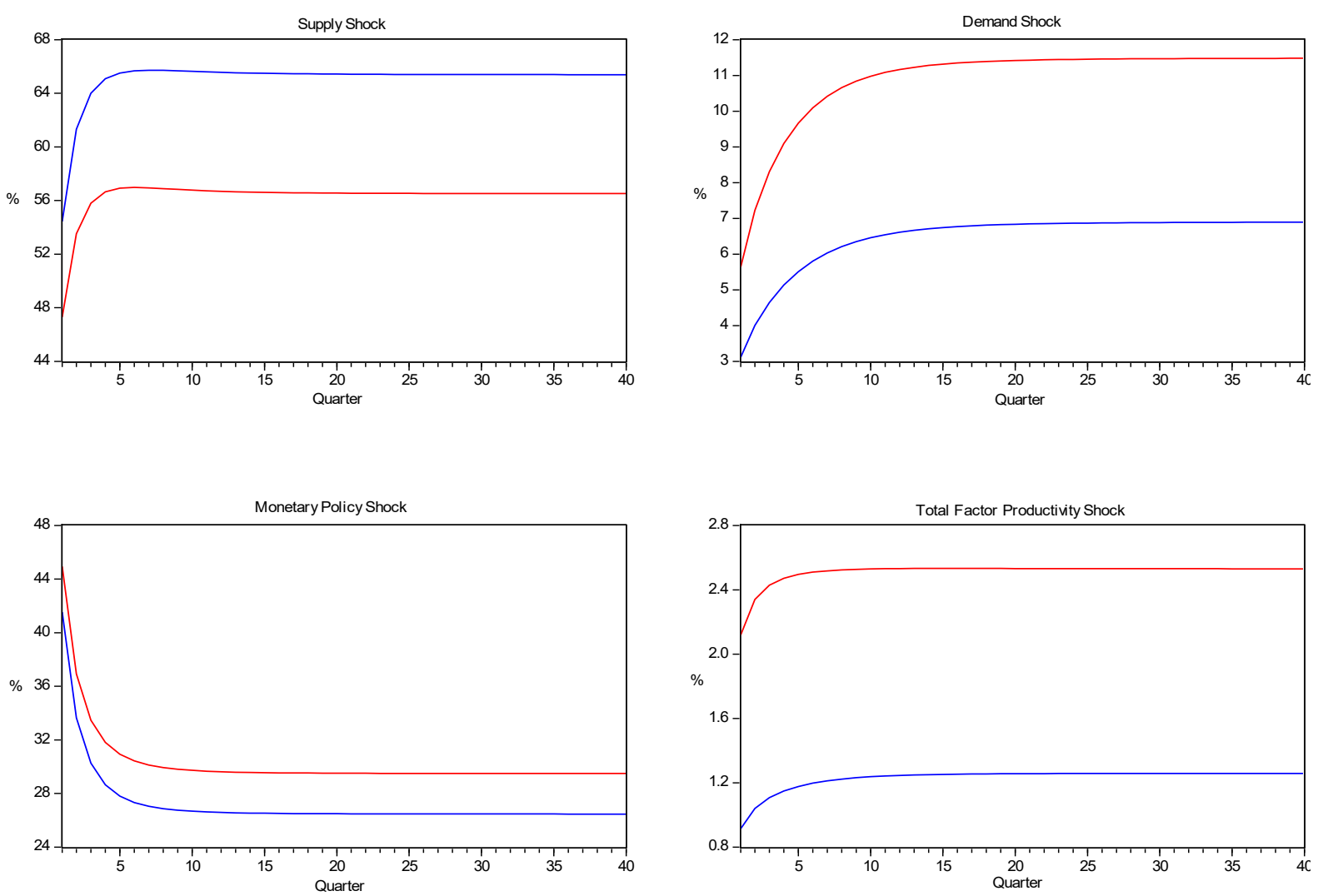
- Aggressive Monetary Policy Model
Benchmark Model

Figure 9: Conditional Forecast Error Variance Decomposition of Interest Rate
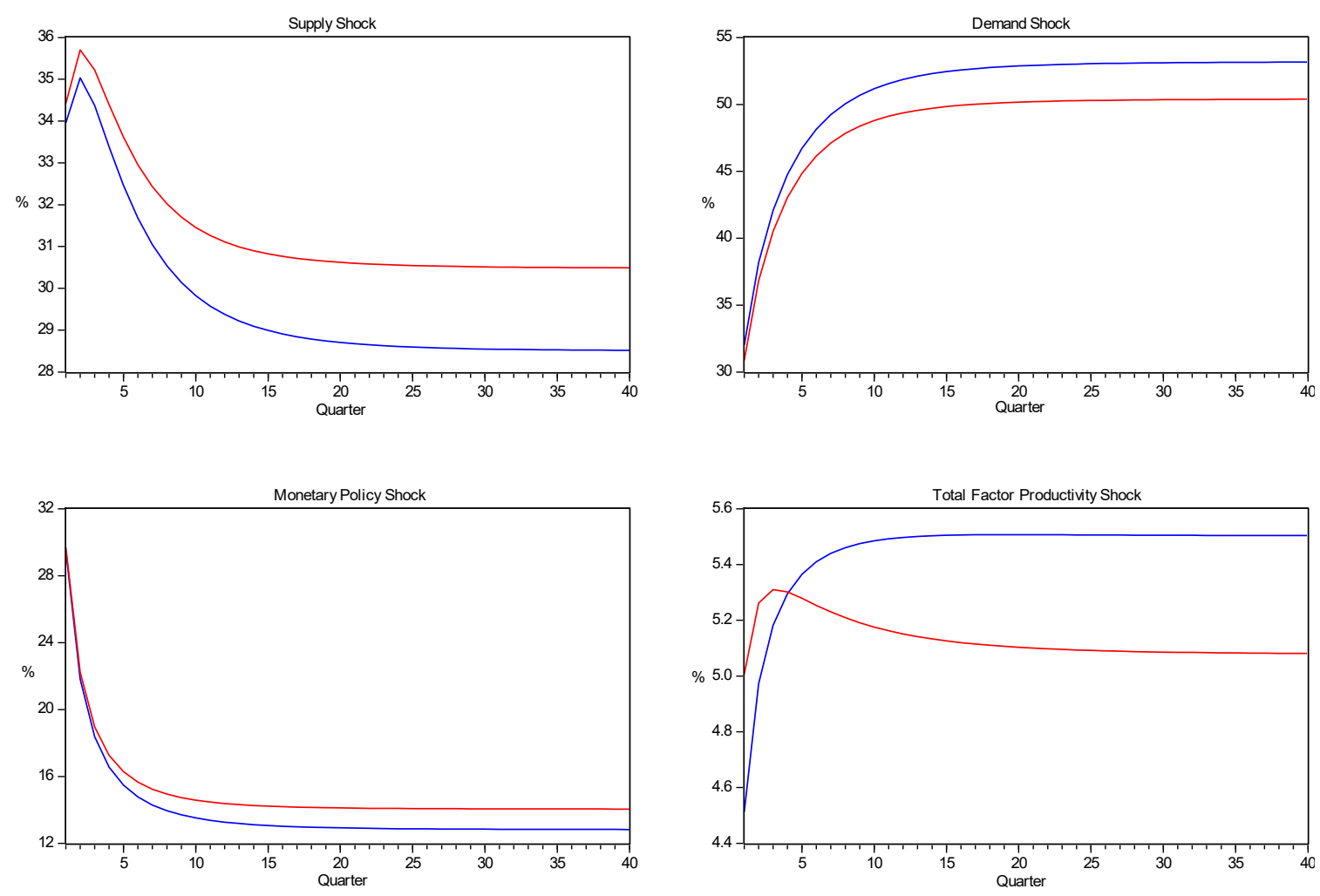

Aggressive Monetary Policy Model BenchmarkModel 
Figure 10: Conditional Forecast Error Variance Decomposition of Inflation
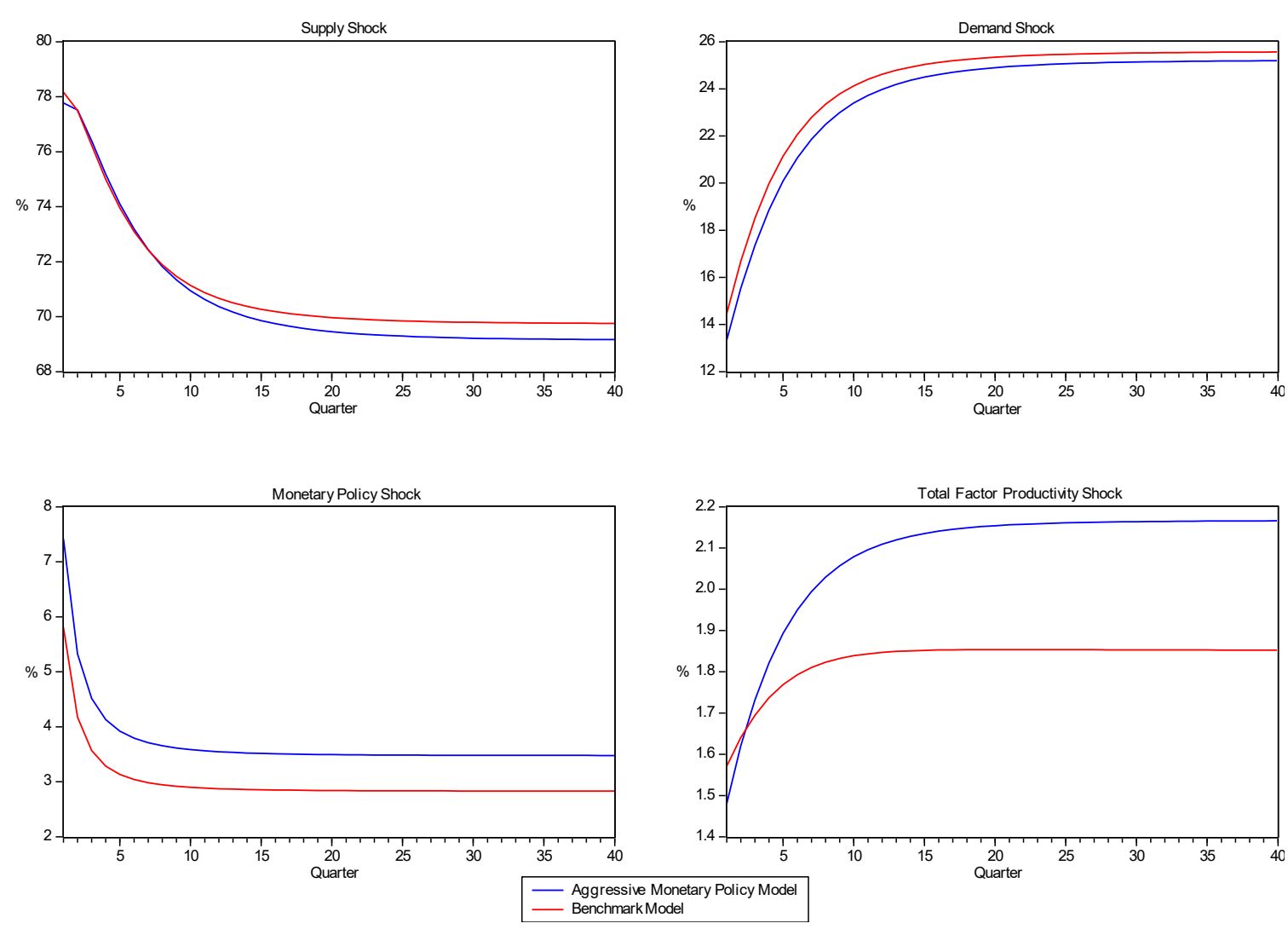

\section{Conclusion}

The potential effects of an aggressive monetary policy on the macroeconomic dynamics is of great importance for the public opinion, investors and governments. Nevertheless, monetary authorities in emerging countries are often criticized both on the basis of their timing and degree of their aggressiveness in changing policy interest rates. Thus, on the back of this observation, we examine the impact of the aggressiveness of monetary authority on the effects of structural shocks in Turkey. To do this, we estimate the basic new Keynesian model by employing Bayesian techniques for Turkey during the period of 2000Q1 to 2019Q1. The Bayesian IRFs give the results which are coherent with the new Keynesian theory. Furthermore, the historical shock decompositions of endogenous variables enable us to grasp the dynamics of Turkish economy in terms of structural shocks over twenty years. The empirical results indicate that the level of inflation stability policy improves in consequence of increasing the aggressiveness of monetary policy in Turkey.

Besides, we find that the aggressive monetary policy increases the effects of monetary policy shock on inflation while its impact on output gap and interest rate decreases at every quarter. Thus, the monetary policy committee of CBT should be meticulous in deciding to raise the aggressiveness of their policies.

As we mentioned earlier, most of the new Keynesian macroeconomic models make use of this model as their starting point. In spite of its simple framework, this model generates practical results which explain the dynamics of the Turkish economy in terms of structural shocks. Nevertheless, one should note that in order to properly examine the potential effects of the aggressiveness of monetary authorities in emerging countries, different characteristics of small open economies, financial frictions and heterogeneous agents should be included in the basic new Keynesian model. Then, the resulting model can be extended to the multi-country version so as to investigate the transmission of structural shocks across economies.

\section{Acknowledgement}

The authors are grateful to the Dynare Team and Johannes Pfeifer from University of Cologne for his precious materials about Dynare. We also thank Mete Han Yağmur from Istanbul Technical University and Vildan Merve Yılmaz from Erzurum Technical University for their helpful comments. 
Adjemian, S. et al. (2018) 'Dynare: reference manual version 4', Dynare Working Paper Series, (1), pp. 1-202. Available at: https://ideas.repec.org/p/cpm/dynare/o01.html.

An, S. and Schorfheide, F. (2007) 'Bayesian Analysis of DSGE Models', Econometric Reviews, 26(2-4), pp. $113-172$.

Benchimol, J. and Fourçans, A. (2012) 'Money and risk in a DSGE framework: A Bayesian application to the Eurozone', Journal of Macroeconomics. Elsevier Inc., 34(1), pp. 95-111. Available at: http://dx.doi.org/10.1016/j.jmacro.2011.10.003.

Calvo, G. (1983) 'Staggered Prices in a Utility Maximizing Framework', Journal of Monetary Economics, 12(3), pp. 383398.

Castelnuovo, E. (2007) 'Taylor rules and interest rate smoothing in the Euro area', Manchester School, 75(1), pp. 1-16.

Christiano, L., Motto, R. and Rostagno, M. (2008) 'Shocks, structures or monetary policies? The Euro Area and US after 2001', Journal of Economic Dynamics and Control, 32(8), pp. 2476-2506.

Dejong, D. N. and Chetan, D. (2007) Structural Macroeconometrics. New Jersey: Princeton University Press.

Fernández-Villaverde, J. (2010) 'The econometrics of DSGE models', Journal of the Spanish Economic Association, 1(12), pp. 3-49.

Gali, J. (2008) Monetary Policy, Inflation and the Business Cycle: An Introduction to the New Keynesian Framework. 1 st edn. New Jersey: Princeton University Press.

Gali, J. (2015) Monetary Policy, Inflation and the Business Cycle: An Introduction to the New Keynesian Framework and Its Applications. 2nd edn. New Jersey: Princeton University Press.

Guerron-Quintana, P. A. and Nason, J. M. (2013) 'Bayesian Estimation of DSGE models', in Hashimzade, N. and Thornton, M. A. (eds) Handbook of Research Methods and Applications in Empirical Macroeconomics. Cheltenham: Edward Elgar Publishing Limited, pp. 486-512.

Lei, X. and Tseng, M. C. (2019) “Wait-And-See” Monetary Policy', Macroeconomic Dynamics, 23(5), pp. 1793-1814.

Pfeifer, J. (2017) An Introduction to Graphs in Dynare. Available at: https://sites.google.com/site/pfeiferecon/dynare.

Pfeifer, J. (2018) A Guide to Specifying Observation Equations for the Estimation of DSGE Models, University of Mannheim Working Paper. Available at: https://sites.google.com/site/pfeiferecon/dynare.

Popescu, I. V. (2014) 'The impact of the recent global crisis on the prioritization of central banks final objectives. A structural approach in the context of Central and Eastern European states', International Journal of Economic Sciences and Applied Research, 7(2), pp. 51-76.

Poutineau, J.-C., Sobczak, K. and Vermandel, G. (2015) 'The analytics of the New Keynesian 3-equation model', Economics and Business Review, 2(2015), pp. 110--129.

Roberts, G. O., Gelman, A. and Gilks, W. R. (1997) 'Weak Convergence and Optimal Scaling of Random Walk Metropolis Algorithms', The Annals of Applied Probability, 7(1), pp. 110-120.

Smets, F. and Wouters, R. (2003) 'An estimated dynamic stochastic general equilibrium model of the euro area', Journal of the European Economic Association, 1(5), pp. 1123-1175.

Smets, F. and Wouters, R. (2007) 'Shocks and frictions in US business cycles: A Bayesian DSGE approach', American Economic Review, 97(3), pp. 586-606.

Taylor, J. B. (1993) 'Discretion versus Policy Rules in Practice', in Carnegie-Rochester Conference Series on Public Policy 39. North-Holland: Elsevier B.V., pp. 195-214.

Taylor, J. B. (1999) 'A Historical Analysis of Monetary Policy Rules', in Taylor, J. B. (ed.) Monetary Policy Rules. Chicago: University of Chicago Press, pp. 319-341.

Walsh, C. E. (2003) Monetary Theory and Policy. 2nd edn. London: The MIT Press.

Woodford, M. (1999) 'Optimal Monetary Policy Inertia', The Manchester School, 67(1), pp. 1-35.

Yağmur, M. H. (2015) 'Monetary Policy and the 2007-08 Global Financial Crisis: an Overview', Finansal Araştırmalar ve Çalı̧̧malar Dergisi, 7(12), pp. 227-243. 